\title{
Intermetallic Phase on the Interface of Ag-Au-Pd/Al Structure
}

\author{
Hao-Wen Hsueh, ${ }^{1}$ Fei-Yi Hung, ${ }^{1}$ Truan-Sheng Lui, ${ }^{1}$ Li-Hui Chen, ${ }^{1}$ and Kuan-Jen Chen ${ }^{2}$ \\ ${ }^{1}$ Department of Materials Science and Engineering, National Cheng Kung University, Tainan 701, Taiwan \\ ${ }^{2}$ The Instrument Center, National Cheng Kung University, Tainan 701, Taiwan \\ Correspondence should be addressed to Fei-Yi Hung; fyhung@mail.ncku.edu.tw
}

Received 23 September 2013; Revised 16 November 2013; Accepted 25 November 2013; Published 2 March 2014

Academic Editor: Pavel Lejcek

Copyright (C) 2014 Hao-Wen Hsueh et al. This is an open access article distributed under the Creative Commons Attribution License, which permits unrestricted use, distribution, and reproduction in any medium, provided the original work is properly cited.

\begin{abstract}
Three wires, $\mathrm{Au}, \mathrm{Cu}$, and $\mathrm{Ag}-\mathrm{Au}-\mathrm{Pd}$, were bonded on an $\mathrm{Al}$ pad, inducing IMC growth by a $155 \mathrm{hr}$ high temperature storage (HTS) so that the electrical resistance was increased and critical fusing current density (CFCD) decreased. Observations of the Ag-AuPd wire after HTS $(0-1000 \mathrm{hr})$ indicated that IMC between the Ag-Au-Pd wire and $\mathrm{Al} \mathrm{Pad} \mathrm{was} \mathrm{divided} \mathrm{into} \mathrm{three} \mathrm{layers:} \mathrm{Ag}_{2} \mathrm{Al}$ layers above and below the bonding interface and a polycrystal thin layer above the total IMC. A high percentage of Pd and Au existed in this $200 \mathrm{~nm}$ thin layer, and could suppress Al diffusion into the Ag matrix to inhibit IMC growth. After PCT-1000 hr, a noncontinuous structure still remained between the IMC layer and interface, and the main phase of IMC was $(\mathrm{Ag}, \mathrm{Au}, \mathrm{Pd})_{2} \mathrm{Al}$ with a hexagonal structure.
\end{abstract}

\section{Introduction}

In the past, gold wire was the primary bonding wire used in the packaging industry; however, low-cost copper wires have been increasingly applied due to gold's ever-higher cost. Unfortunately, copper wire cannot fully replace gold wire due to some disadvantages, such as easy oxidation and high hardness [1]. Despite both the prices and hardness of silver wire, which exhibits excellent electrical conductivity, being between gold and copper, the high temperature oxidation problem still exists in silver wire, and the mechanism of the intermetallic compound layer (IMC) on the bonding interface is still unknown. In this study, to enhance the reliability of silver wire in the wire bonding process, $8 \mathrm{wt} . \%$ $\mathrm{Au}$ and $3 \mathrm{wt} . \%$ Pd were added to pure silver to reduce oxidation and inhibit the growth of intermetallic compounds (IMCs).

Research has [2-4] indicated that IMCs form in the bonding interface due to the diffusion mechanism of different metals, which become significant when the temperature increases. After a long-term high temperature storage (HTS), IMCs formed in the bonding interface between the gold wire and aluminum substrate, such as $\mathrm{Au}_{4} \mathrm{Al}$ and $\mathrm{Au}_{5} \mathrm{Al}$. In previous research [2], IMCs were found to have high electrical resistance, and the IMC growth rate of gold and aluminum was ten times that of copper and aluminum. In practical applications, the total electrical resistance $\left(\Omega_{\text {wire }}+\right.$ $\Omega_{\text {IMC }}+\Omega_{\text {Al pad }}=\Omega_{\text {total }}$ ) was affected by both of the structure and thickness of the IMCs. It has been suggested that the relationship of the bonding interface electrical resistance and IMC structure of silver alloy wire with aluminum substrate is important $[5,6]$. The interface mechanism is able to provide a reference for packaging.

\section{Experimental Procedure}

In this study, three wires, $\mathrm{Ag}-8 \mathrm{Au}-3 \mathrm{Pd}, \mathrm{Au}$, and $\mathrm{Cu}$ were chosen to compare the variations of total electrical resistance and critical fusing current density (CFCD). $\mathrm{HTS}$ at $175^{\circ} \mathrm{C}$ and $155 \mathrm{hr}$ was the primary method to accelerate the growth of IMC between the wires and $\mathrm{Al}$ pad [7]. Leading the directing current into the as-bonded samples was called the directing current test, the circuit mechanism of which is shown in Figure 1. Variations of total electrical resistance $\left(\Omega_{\text {total }}=\right.$ $\left.\Omega_{\text {wire }}+\Omega_{\mathrm{IMC}}+\Omega_{\mathrm{Al} \mathrm{pad}}\right)$ and CFCD of the as-bonded wire with HTS of each wire were compared. The voltage was increased $0.05 \mathrm{~V} / \mathrm{sec}$ until the wire fused at the $\mathrm{CFCD}\left(\mathrm{A} / \mathrm{m}^{2}\right)$. 


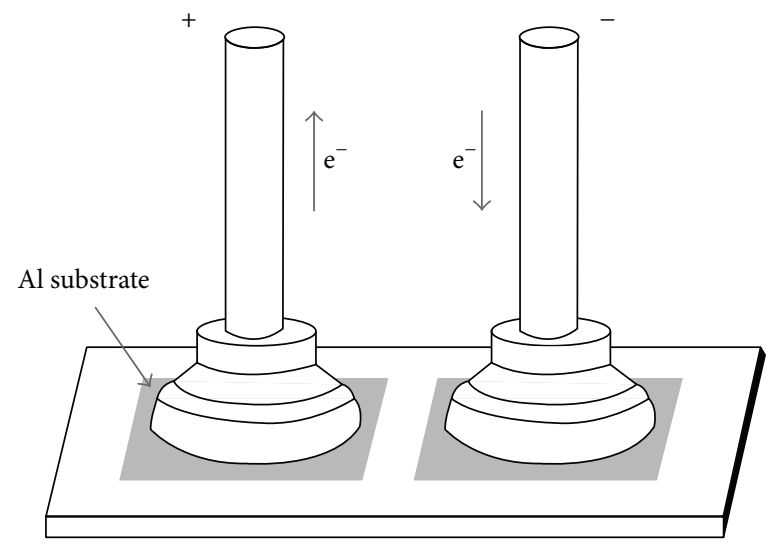

FIGURE 1: Electrical mechanism diagram of wire bonding interface device.

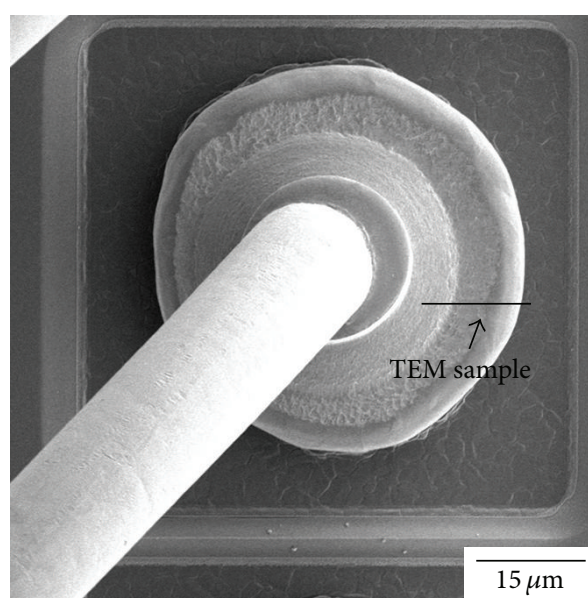

(a)

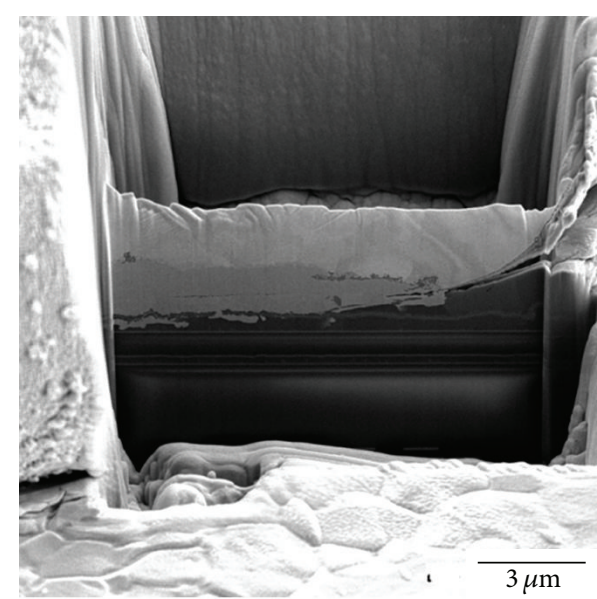

(b)

FIGURE 2: (a) Black line indicates the position of TEM sample by using FIB and (b) shows the shape of the TEM sample.

High temperature storage (HTS) is a reliability test with long duration under high temperature. In order to understand the relation between the electrical resistance and IMC growth after HTS, the Ag-8Au-3Pd wire was bonded on the Al substrate and HTS was executed at $175^{\circ} \mathrm{C}$ for $250 \sim 1000$ hours, and IMCs at the interface were observed by focused ion beam (FIB). The $1000 \mathrm{hr}$ HTS specimen was chosen for IMC structure analysis, using FIB to produce a $10 \mu \mathrm{m} \times 5 \mu \mathrm{m} \times$ $40 \mathrm{~nm}$ TEM sample, the position of which is illustrated with a black line in Figure 2(a) while the morphology is presented in Figure 2(b). The crystal structure was confirmed by EDS and selected area electron diffraction (SAED).

\section{Results and Discussions}

3.1. Electrical Properties of Wire Structure. Figure 3 shows the electrical properties of the three devices (wire + IMC $+\mathrm{Al}$ pad); before HTS, the Cu device had the lowest electrical resistance and the highest CFCD, while data from the gold and silver alloy wires were similar. After HTS, the resistance increased and CFCD decreased. The HTS temperature was too low for recrystallization $[1,4]$, and the IMC characteristics of the interface after HTS were the main factor affecting the electrical properties.

After HTS, the total electrical resistance of the copper device increased due to the IMC $(\mathrm{Cu}-\mathrm{Al})$ growth between the copper wire and aluminum pad [8]. The change of electrical resistance on the silver alloy and gold wire was limited because the growth mechanism of IMC was different. Compared to the gold and silver alloy wires, both the resistance and CFCD of the silver alloy wire were better than that of the gold wire. After extending the HTS duration (0$1000 \mathrm{hr}$ ) of the silver alloy wire, the IMC growth mechanism and phase structure of the Ag-Al IMC were analyzed.

3.2. IMC of $A g-8 A u-3 P d$ Wire. At room temperature, the bonded interface was continuous, and IMC did not continue to grow, as shown in Figure 4(a). After HTS, the IMC growth characteristics of $250 \mathrm{hr}, 500 \mathrm{hr}, 750 \mathrm{hr}$, and $1000 \mathrm{hr}$ were examined, as presented in Figures 4(b)-4(e). IMC grew 


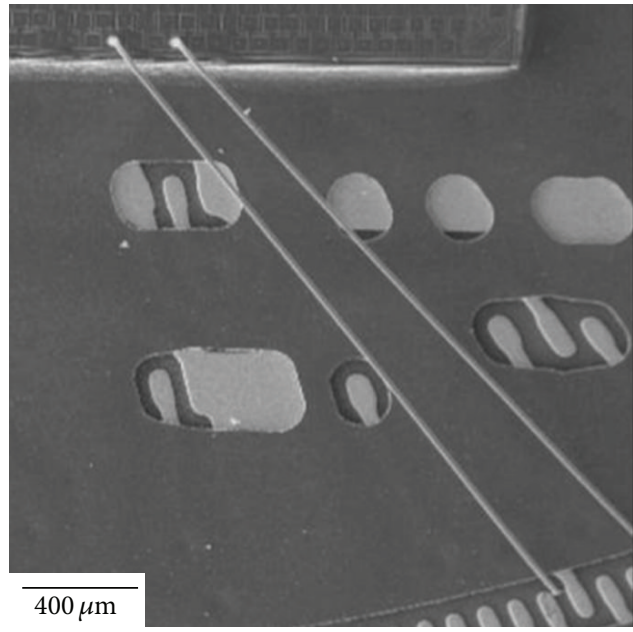

(a)

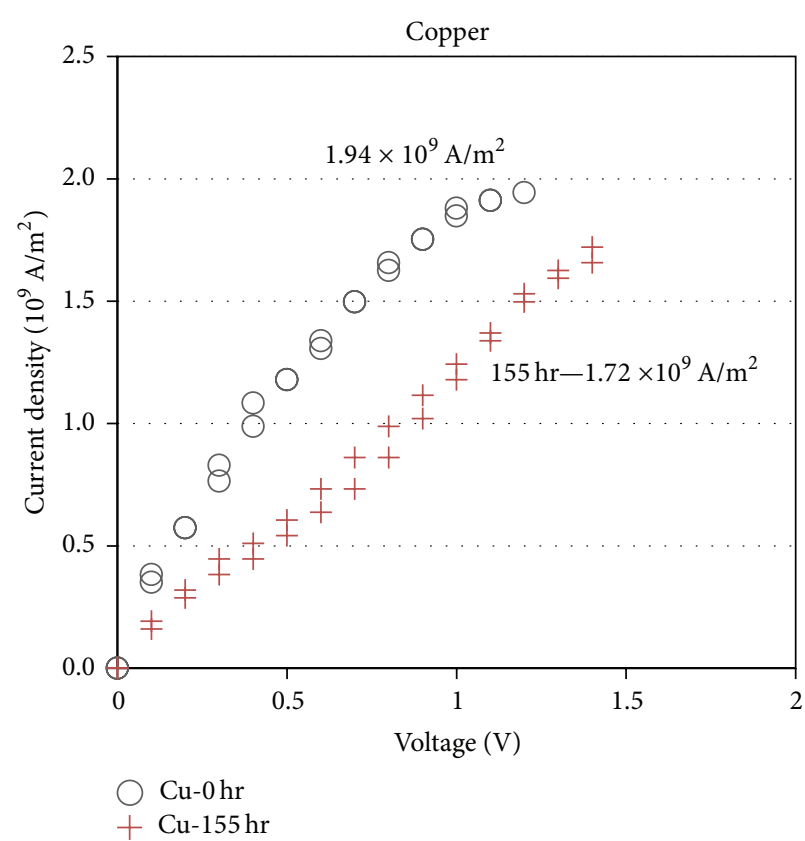

(c)

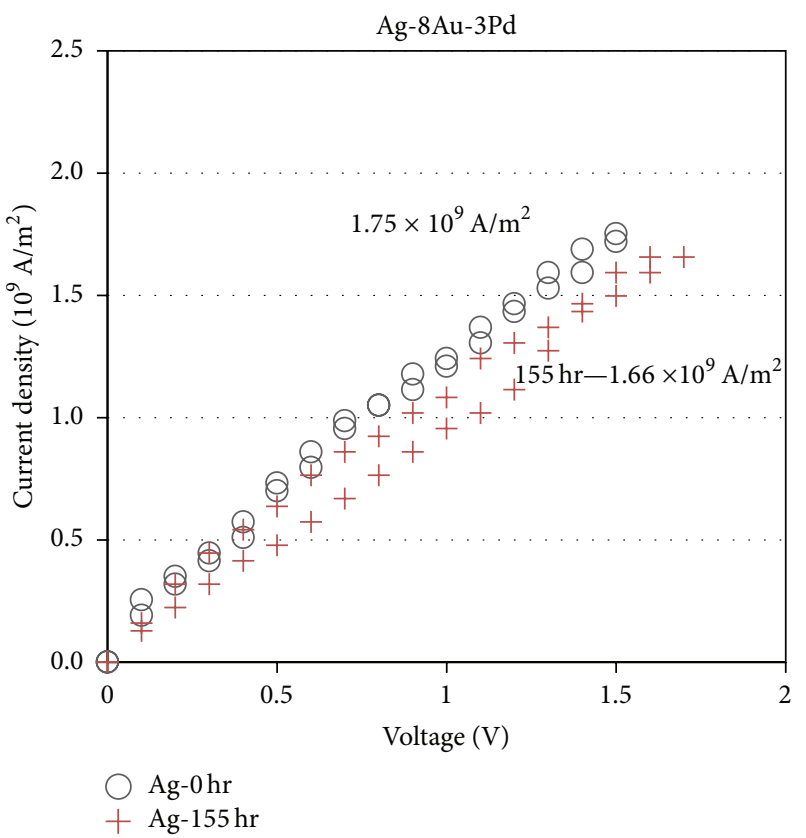

(b)

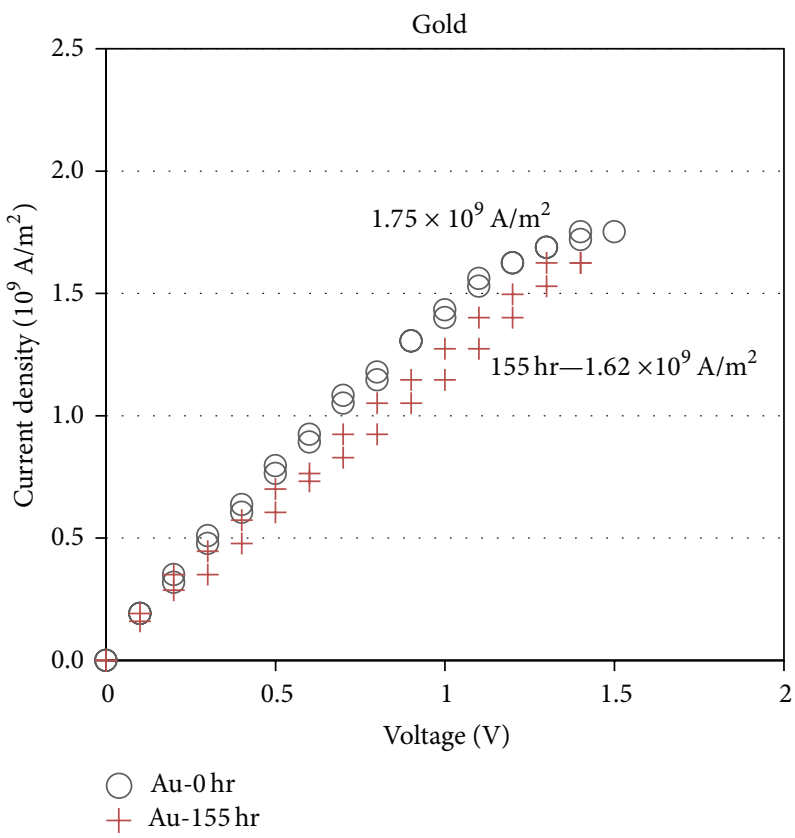

(d)

FIGURE 3: (a) I-V curve method and the results of (b) Ag-8Au-3Pd, (c) copper, and (d) gold wires.

significantly in the HTS- $250 \mathrm{hr}$ process, and the total IMC thickness layer was $1-1.5 \mu \mathrm{m}$, and did not increase with an increased HTS duration, which indicates that the IMC growth kinetics were suppressed effectively. In addition, IMC had a noncontinuous distribution in the bonding interface and was separated into two layers. When the HTS duration was $500 \mathrm{hr}$, Kirkendall voids began to form above the IMC [7]. There is strong evidence indicating that IMCs were formed at the zone of maximum pressure at the bonding interface and diffused up and down progressively to form a coarseribbon shaped IMC. Due to Al diffusion exceeding Ag, large amounts of Kirkendall voids appeared by increasing the HTS duration to $500 \mathrm{hr}$. After HTS-1000 hr, Kirkendall voids could not propagate to form Kirkendall cracks. It is clear that this interface diffusion path was suppressed so that the IMC thickness and Kirkendall voids cannot increase.

The HTS-1000 hr specimen displayed no significant oxidation behavior, which confirms that oxidation resistance of 

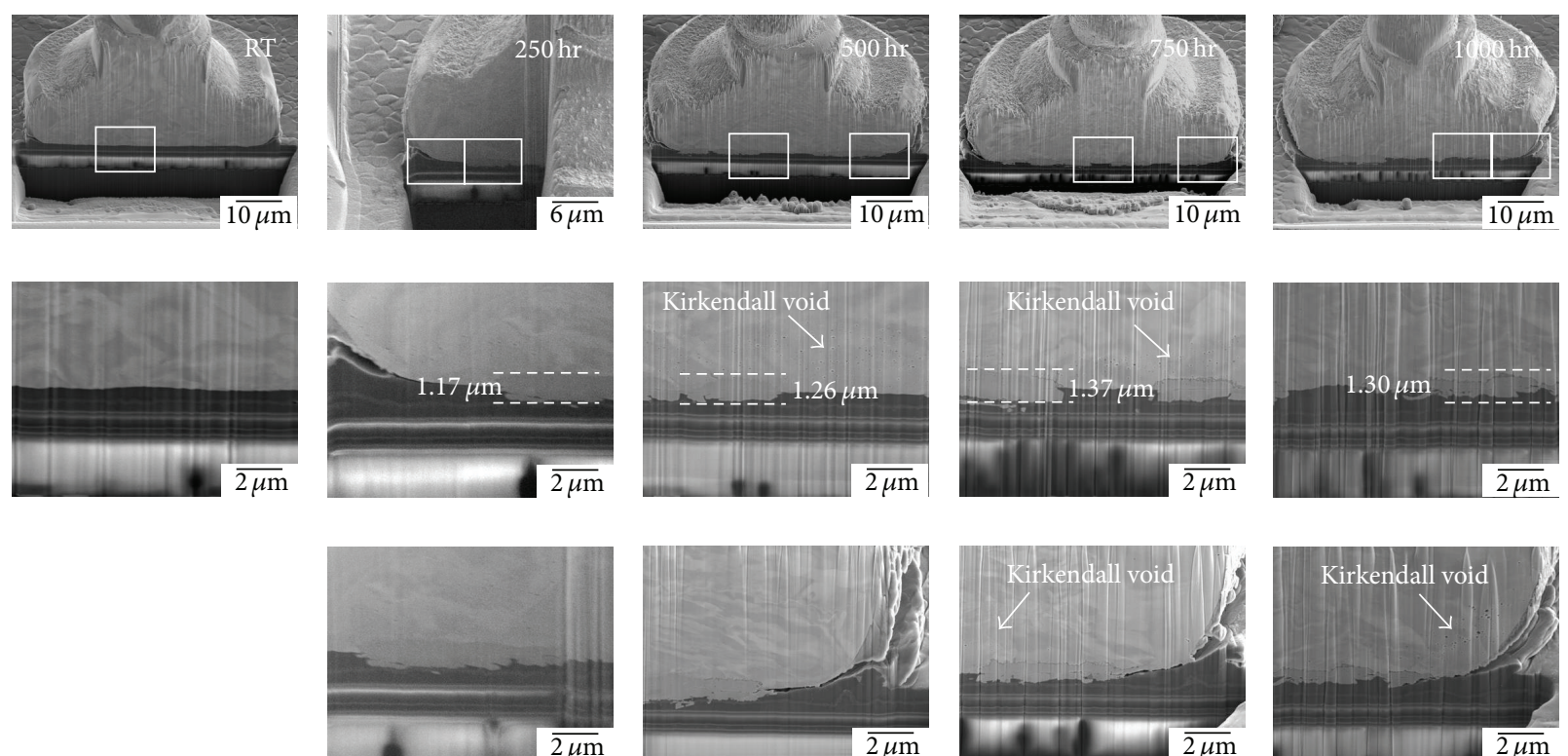

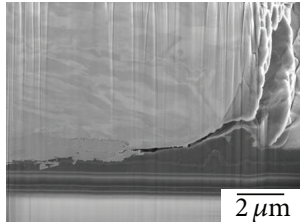

(b)

(c)

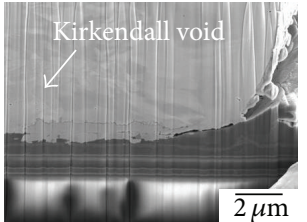

(d)

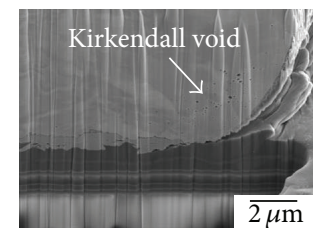

(e)

FIGURE 4: Observations of bonding interface cross-section featured the following conditions: (a) as-bonded interface at room temperature. Intermetallic compounds were grown for (b) $250 \mathrm{hr}$, (c) $500 \mathrm{hr}$, (d) $750 \mathrm{hr}$, and (e) $1000 \mathrm{hr}$.

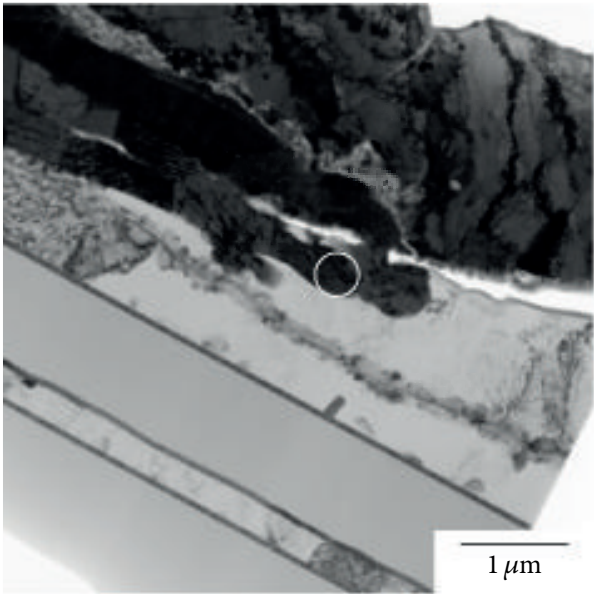

(a)

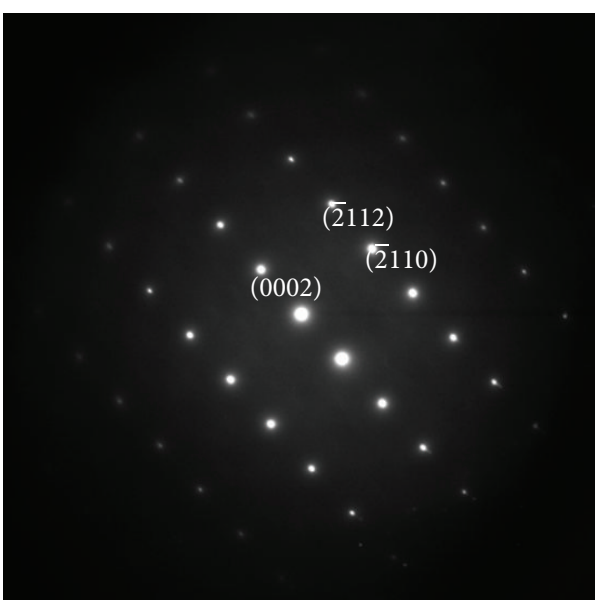

(c)

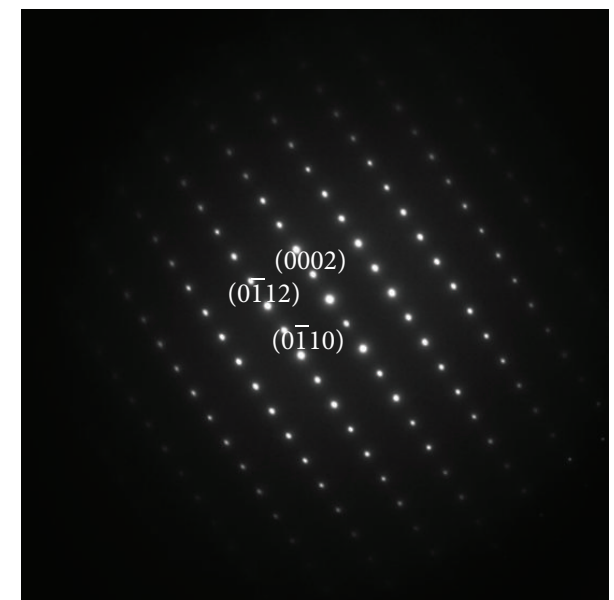

(b)

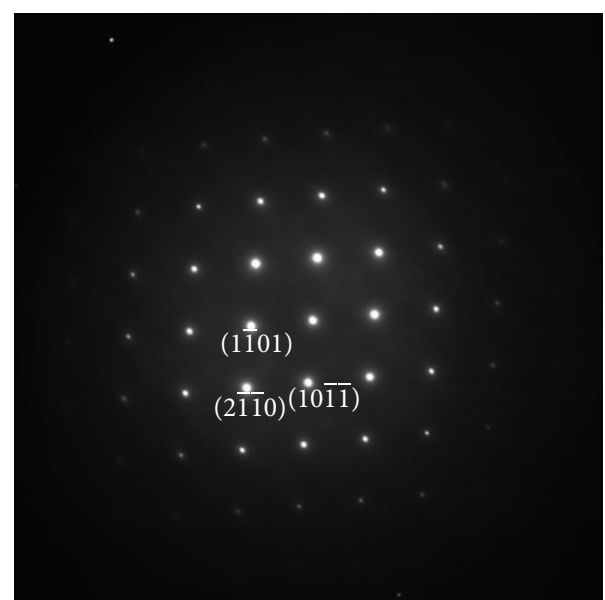

(d)

FIGURE 5: IMCs below the bonding interface were found to be $\mathrm{Ag}_{2} \mathrm{Al}$ (hexagonal structure). 


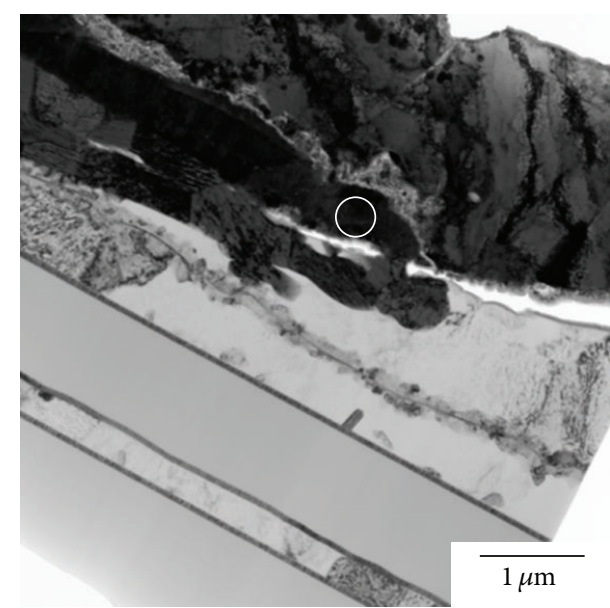

(a)

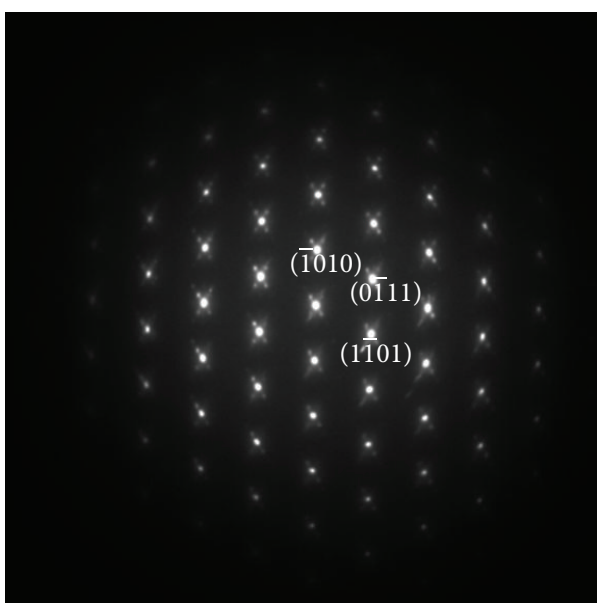

(c)

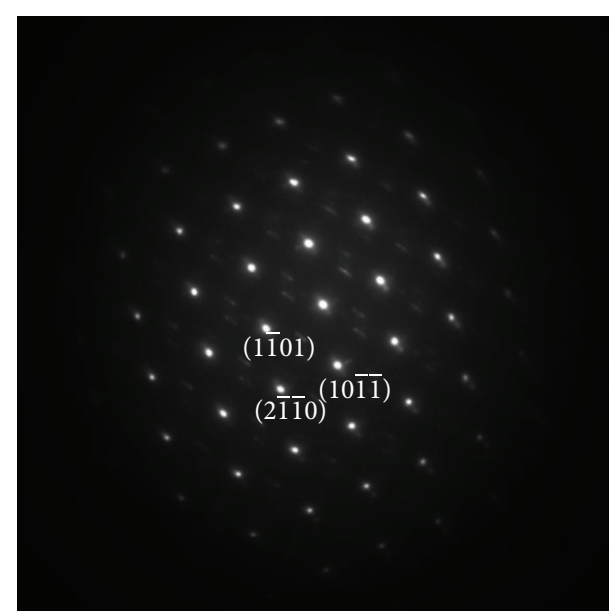

(b)

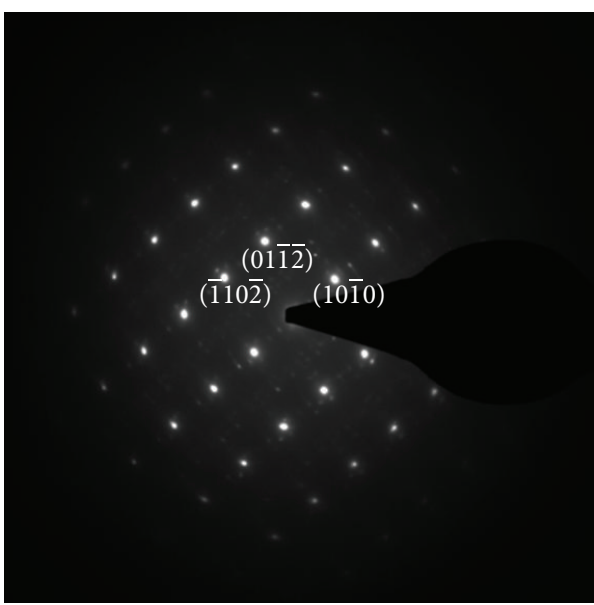

(d)

Figure 6: IMCs above the bonding interface were found to be ( $\mathrm{Ag}, \mathrm{Au}, \mathrm{Pd})_{2} \mathrm{Al}$ (hexagonal structure).

TABLE 1: EDS of the three layers of IMC (wt.\%).

\begin{tabular}{lcccc}
\hline & $\mathrm{Al}$ & $\mathrm{Ag}$ & $\mathrm{Au}$ & $\mathrm{Pd}$ \\
\hline H phase & $60.50 \%$ & $22.80 \%$ & $10.89 \%$ & $5.81 \%$ \\
Upper IMC & $43.07 \%$ & $44.02 \%$ & $8.25 \%$ & $4.66 \%$ \\
Lower IMC & $37.26 \%$ & $62.74 \%$ & & \\
\hline
\end{tabular}

the Ag-8Au-3Pd wire was improved. The bonding interface was analyzed by TEM and showed that the IMCs were divided into three layers: lower IMC, upper IMC, and the thin film above the total IMC. Figures 5(b)-5(d) and Table 1 offer the selected area electron diffraction patterns and EDS results of the lower IMC, which confirm that the lower IMC was $\mathrm{Ag}_{2} \mathrm{Al}$ with a hexagonal structure. Furthermore, Table 1 and Figure 6 indicate that the upper IMC was $\mathrm{Ag}_{2} \mathrm{Al}$ doped $\mathrm{Au}$ and $\mathrm{Pd}$ with a hexagonal structure. This result indicates that both the $\mathrm{Au}$ and Pd cannot diffuse into the lower IMC. Notably, a thin film above the upper IMC exists, as shown in Figure 7. In this area, much $\mathrm{Al}$ accumulated, which was confirmed as a rich-Al thin film that had a four-element polycrystalline phase (named $\mathrm{H}$ phase) by SAED. More noteworthy is that most of the $\mathrm{Al}$ was limited in this $\mathrm{H}$ phase and could not form new IMCs. Moreover, the IMC layer could not be thickened after HTS.

\section{Conclusion}

With a circuit device (wire $+\mathrm{IMC}+\mathrm{Al}$ pad) and HTS, the electrical resistance and CFCD value of a silver alloy wire were possible to be measured. The IMC interface between the $\mathrm{Ag}-8 \mathrm{Au}-3 \mathrm{Pd}$ wire and $\mathrm{Al}$ pad has three layers: the lower IMC which is hexagonal $\mathrm{Ag}_{2} \mathrm{Al}$, the upper IMC which is hexagonal $(\mathrm{Ag}, \mathrm{Au}, \mathrm{Pd})_{2} \mathrm{Al}$, and a rich-Al $\mathrm{H}$ phase. The Ag-8Au-3Pd wire has excellent oxidation resistance and the total IMC layer thickness cannot increase when increasing the HTS duration.

\section{Conflict of Interests}

The authors declare that there is no conflict of interests concerning the publication of this paper. 


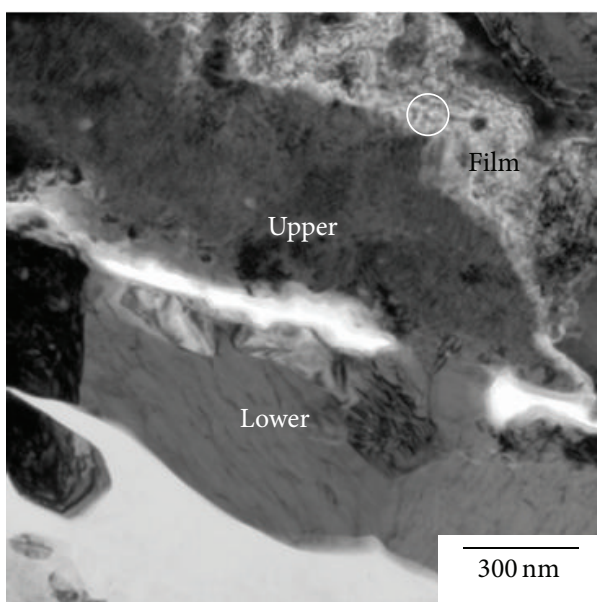

(a)

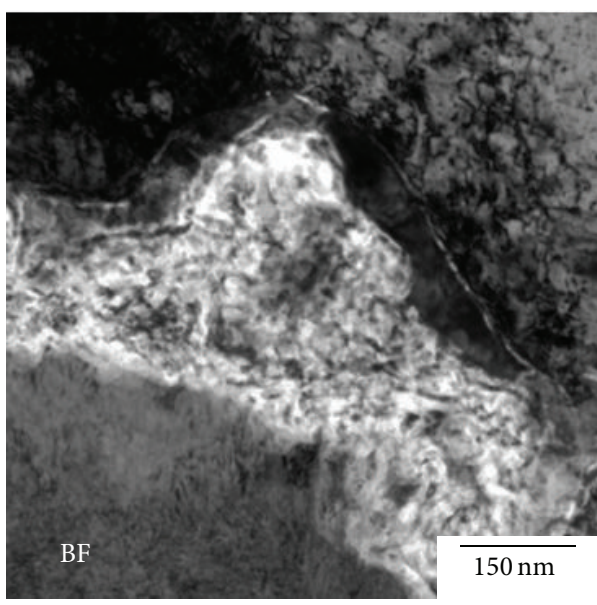

(c)

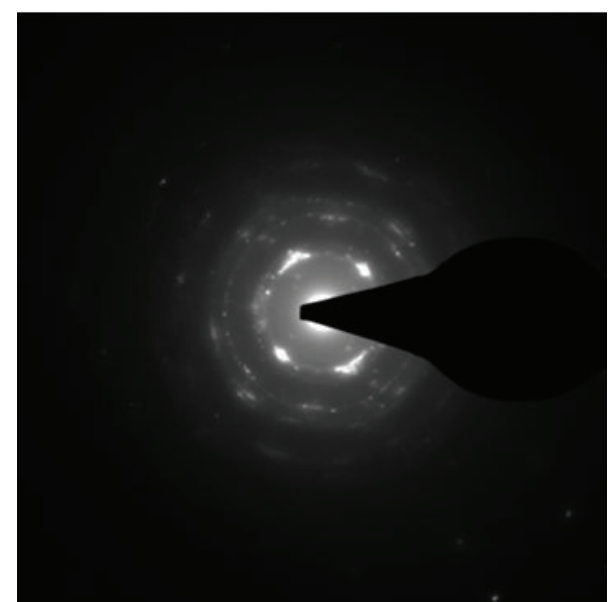

(b)

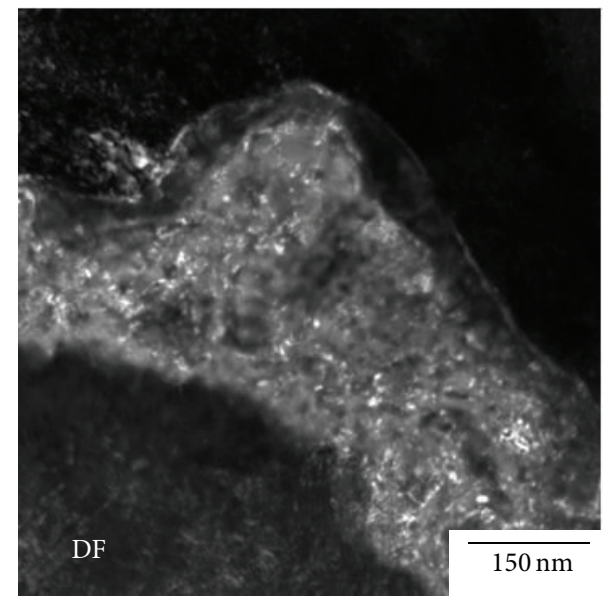

(d)

FIGURE 7: Small upper polycrystal IMC layers.

\section{Acknowledgments}

The authors are grateful to The Instrument Center of National Cheng Kung University, the Center for Micro/Nano Science and Technology (D101-2700), and NSC 102-2221-E-006-061 for the financial support.

\section{References}

[1] I.-T. Huang, F.-Y. Hung, T.-S. Lui, L.-H. Chen, and H.-W. Hsueh, "A study on the tensile fracture mechanism of $15 \mu \mathrm{m}$ copper wire after EFO process," Microelectronics Reliability, vol. 51, no. 1, pp. 25-29, 2011.

[2] H.-J. Kim, J. Y. Lee, K.-W. Paik et al., "Effects of $\mathrm{Cu} / \mathrm{Al}$ intermetallic compound (IMC) on copper wire and aluminum pad bondability," IEEE Transactions on Components and Packaging Technologies, vol. 26, no. 2, pp. 367-374, 2003.

[3] T. C. Wei and A. R. Daud, "Mechanical and electrical properties of $\mathrm{Au}-\mathrm{Al}$ and $\mathrm{Cu}-\mathrm{Al}$ intermetallics layer at wire bonding interface," Journal of Electronic Packaging, vol. 125, no. 4, pp. 617-620, 2003.
[4] C. D. Breach and F. Wulff, "New observations on intermetallic compound formation in gold ball bonds: general growth patterns and identification of two forms of $\mathrm{Au}_{4} \mathrm{Al}$," Microelectronics Reliability, vol. 44, no. 6, pp. 973-981, 2004.

[5] H.-W. Hsueh, F.-Y. Hung, T.-S. Lui, and L.-H. Chen, "Microstructure, electric flame-off characteristics and tensile properties of silver bonding wires," Microelectronics Reliability, vol. 51, no. 12, pp. 2243-2249, 2011.

[6] T.-H. Chuang, H.-C. Wang, C.-H. Tsai et al., “Thermal stability of grain structure and material properties in an annealingtwinned Ag-8Au-3Pd alloy wire," Scripta Materialia, vol. 67, no. 6, pp. 605-608, 2012.

[7] S. Murali, N. Srikanth, and C. J. Vath III, "Effect of wire size on the formation of intermetallics and Kirkendall voids on thermal aging of thermosonic wire bonds," Materials Letters, vol. 58, no. 25, pp. 3096-3101, 2004.

[8] C. J. Hang, C. Q. Wang, M. Mayer, Y. H. Tian, Y. Zhou, and H. $\mathrm{H}$. Wang, "Growth behavior of $\mathrm{Cu} / \mathrm{Al}$ intermetallic compounds and cracks in copper ball bonds during isothermal aging," Microelectronics Reliability, vol. 48, no. 3, pp. 416-424, 2008. 

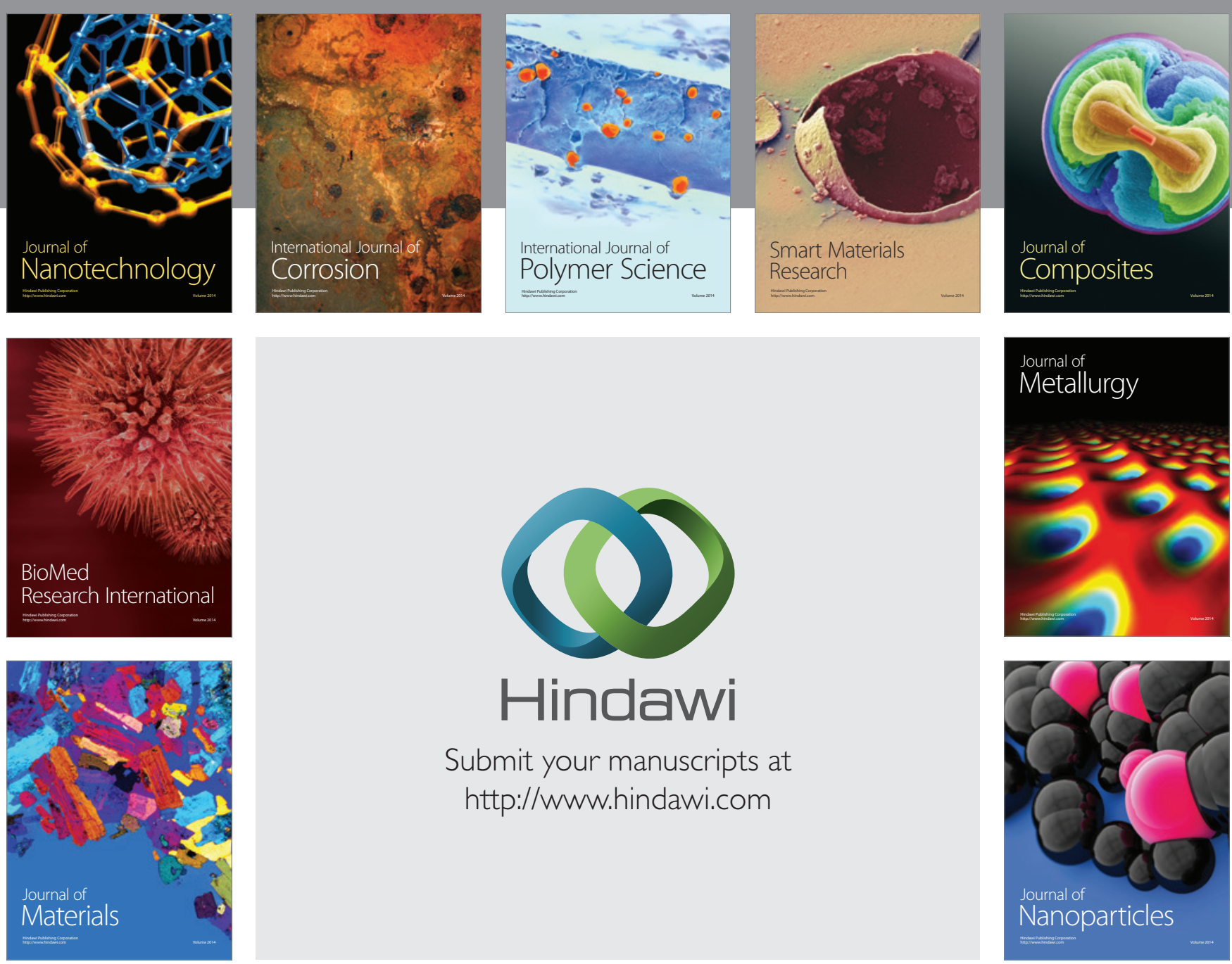

Submit your manuscripts at http://www.hindawi.com
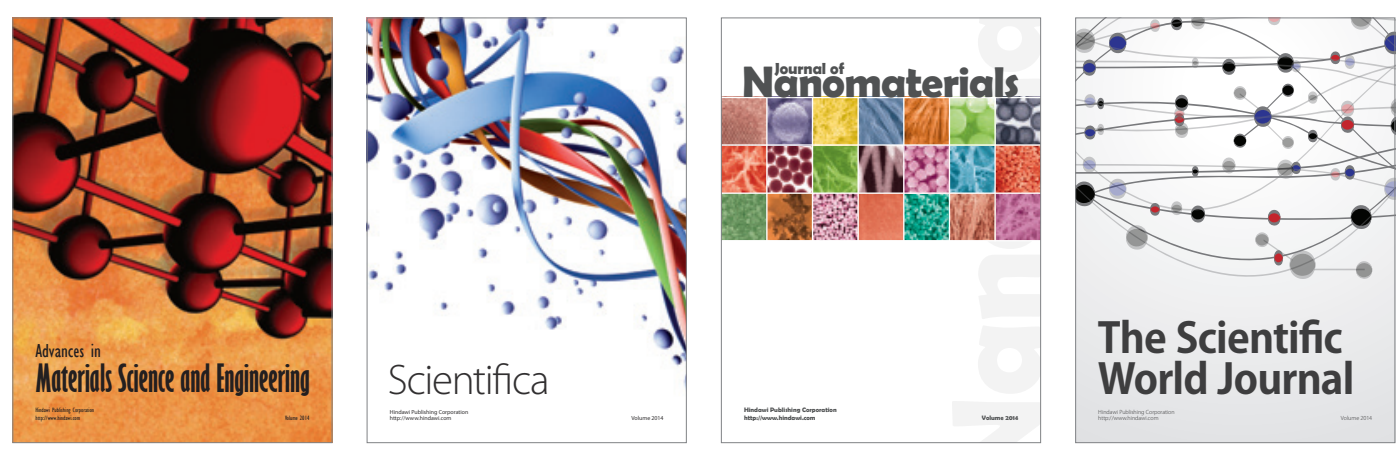

\section{The Scientific World Journal}
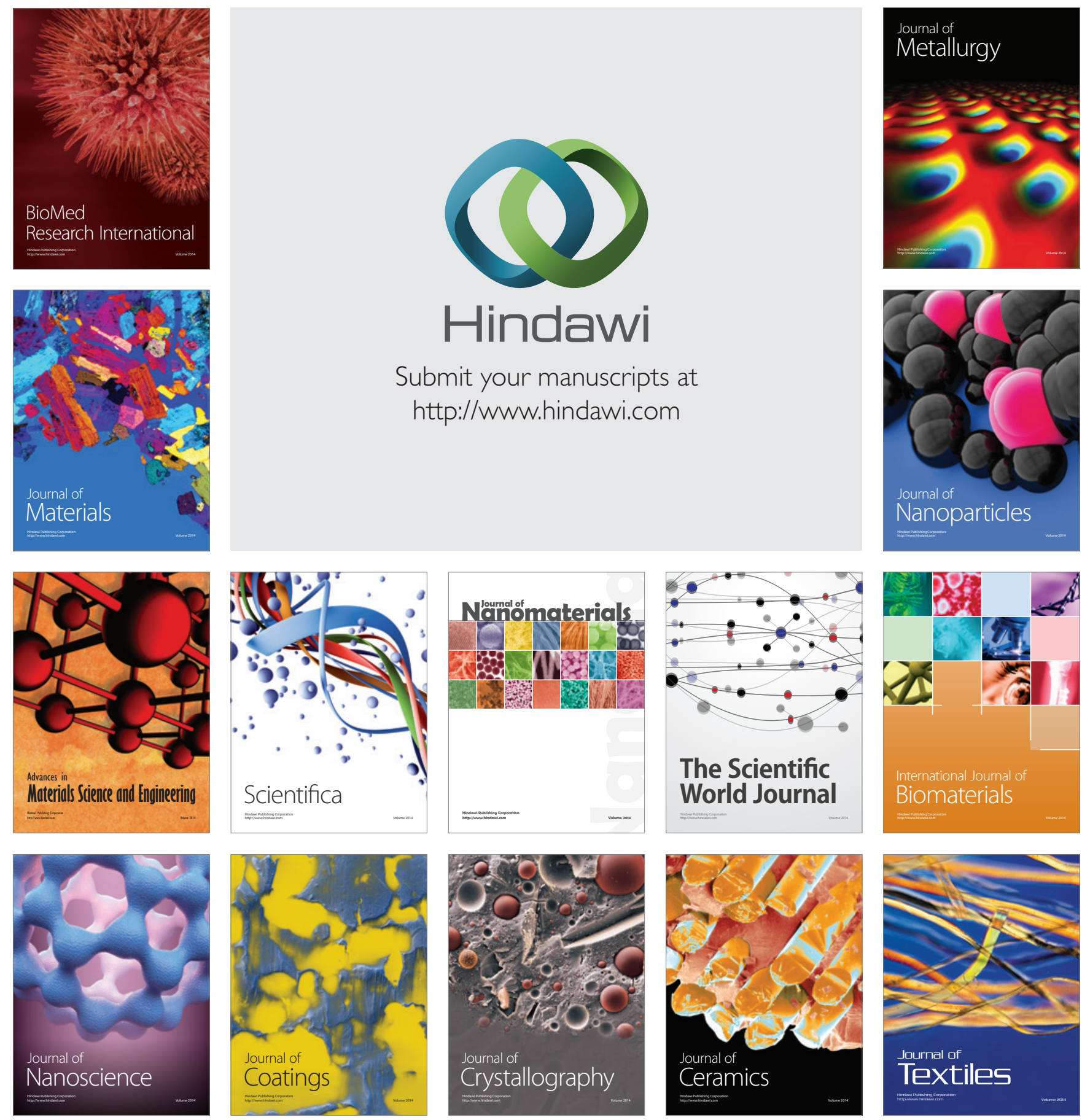